
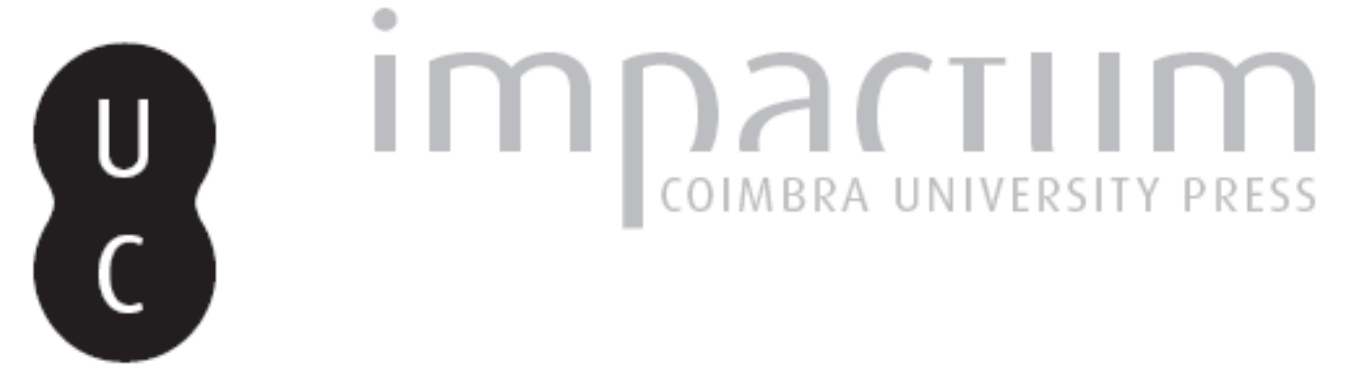

\title{
A crise migratória do Mediterrâneo e os riscos antroposociais
}

\section{Autor(es): $\quad$ Castro, Fátima Velez de}

Publicado por: Associação Portuguesa de Riscos, Prevenção e Segurança; Imprensa

URL

persistente: da Universidade de Coimbra

DOI:

URl:http://hdl.handle.net/10316.2/39733

DOI:https://doi.org/10.14195/1647-7723_23_8

Accessed : $\quad$ 26-Apr-2023 01:21:31

A navegação consulta e descarregamento dos títulos inseridos nas Bibliotecas Digitais UC Digitalis, UC Pombalina e UC Impactum, pressupõem a aceitação plena e sem reservas dos Termos e Condições de Uso destas Bibliotecas Digitais, disponíveis em https://digitalis.uc.pt/pt-pt/termos.

Conforme exposto nos referidos Termos e Condições de Uso, o descarregamento de títulos de acesso restrito requer uma licença válida de autorização devendo o utilizador aceder ao(s) documento(s) a partir de um endereço de IP da instituição detentora da supramencionada licença.

Ao utilizador é apenas permitido o descarregamento para uso pessoal, pelo que o emprego do(s) título(s) descarregado(s) para outro fim, designadamente comercial, carece de autorização do respetivo autor ou editor da obra.

Na medida em que todas as obras da UC Digitalis se encontram protegidas pelo Código do Direito de Autor e Direitos Conexos e demais legislação aplicável, toda a cópia, parcial ou total, deste documento, nos casos em que é legalmente admitida, deverá conter ou fazer-se acompanhar por este aviso.

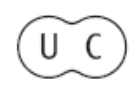




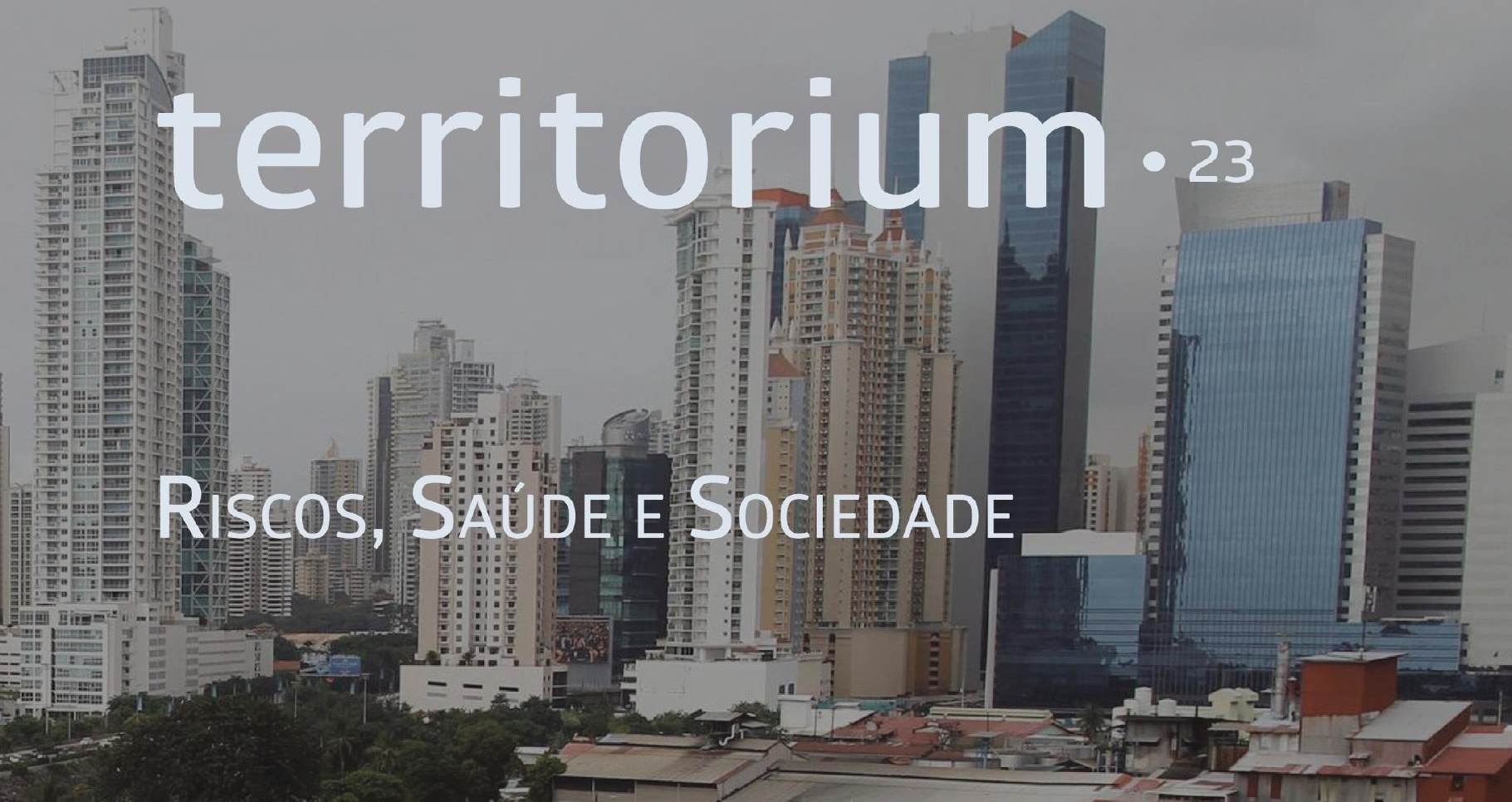

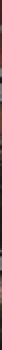

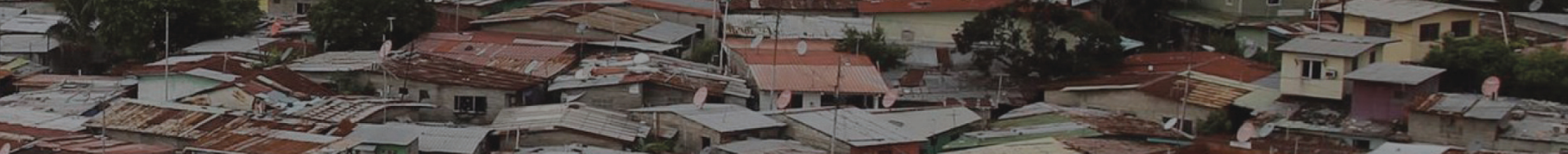

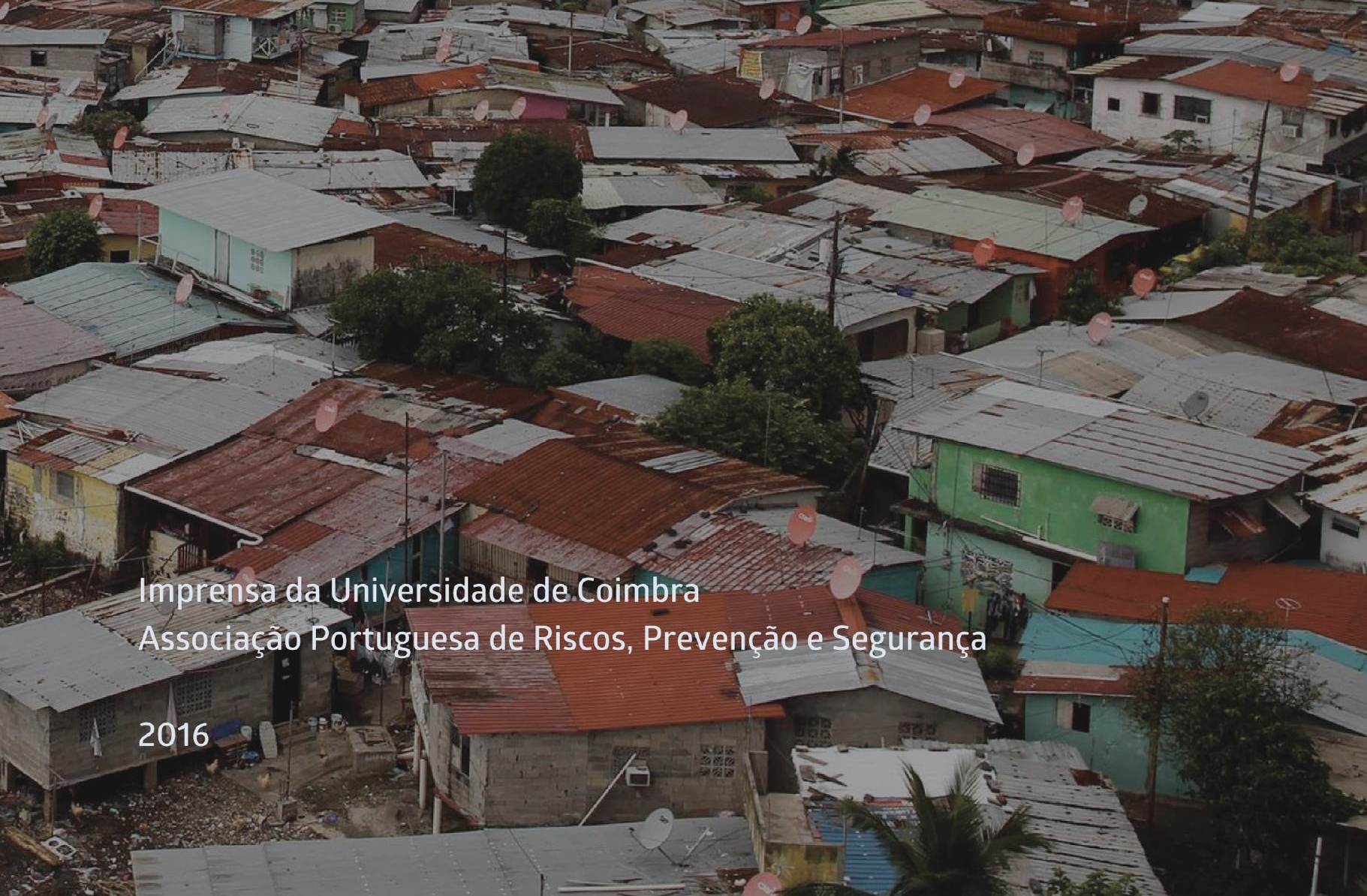




\section{A CRISE MIGRATÓRIA DO MEDITERRÂNEO E OS RISCOS ANTROPOSOCIAIS*}

THE MEDITERRANEAN MIGRATORY CRISIS AND THE ANTHROPOSOCIAL RISKS

Fátima Velez de Castro

Departamento de Geografia e Turismo, CEGOT e RISCOS, Universidade de Coimbra velezcastro@fl.uc.pt

\section{RESUMO}

Este trabalho tem como objetivo refletir sobre a crise migratória do Mediterrâneo, usando dados de 2015, e os riscos sociais inerentes à população migrante, bem como ponderar sobre as consequências da des/reterritorialização destes indivíduos, tendo em conta possíveis estratégias de mitigação de projetos migratórios baseados em ambientes de carência, criminalidade, insegurança e tumulto social.

Palavras-chave: Riscos sociais, convulsões sociais, crise, migrações, Mediterrâneo.

\section{ABSTRACT}

This work aims to discuss about the migration crisis in the Mediterranean, using data from 2015, and the social risks of the migrant population as well as ponder the consequences of the de / reterritorialization of these individuals, taking into account possible mitigation strategies for migration projects based on environments of deprivation, crime, insecurity and social turmoil.

Keywords: Social risk, social conflicts, crisis, migration, Mediterranean.

\section{RESUMEN}

La crisis de la migración en el Mediterráneo, utilizando dados de 2015, y los riesgos antroposociales - Este trabajo tiene como objetivo reflexionar sobre la crisis de la migración en el Mediterráneo y los riesgos sociales de la población migrante, así como sobre las consecuencias de la des/reterritorialización de estas personas, teniendo en cuenta las posibles estrategias de mitigación de proyectos de migración basados en entornos de privación, delincuencia, inseguridad y agitación social.

Palabras clave: Riesgo social, convulsiones sociales, crisis, migración, Mediterráneo.

\section{RESUMÉ}

La crise migratoire dans la Méditerranée et les risques sociaux - Ce travail est une réflexion sur la crise migratoire en Méditerranée et les risques sociaux de la population migrante. C'est une réflexion sur les conséquences de la reterritorialisation de ces personnes, en tenant compte d'éventuelles stratégies d'atténuation dans les projets de migration fondés sur des environnements de privation, de criminalité, d'insécurité et d'agitation sociale.

Mots-clé: Risques sociaux, conflits sociaux, crise, migrations, Méditerranée.

\footnotetext{
* O texto deste artigo corresponde a uma comunicação apresentada no I Seminário da Rede Incêndios-Solo e I Simpósio Ibero-Afro-Americano de Riscos, tendo sido submetido em 30-11-2015, sujeito a revisão por pares a 18-03-2016 e aceite para publicação em 31-03-2016.

Este artigo é parte integrante da Revista Territorium, n. ${ }^{\circ} 23,2016,{ }^{\circ}$ RIscos, ISSN: 0872-8941.
} 


\section{IIntrodução: a necessidade do estudo}

A crise migratória vivida até há alguns meses atrás na região do Mediterrâneo expandiu-se a toda a Europa, sendo alvo de preocupação já fora desta unidade geográfica, pelo disseminar de eventuais consequências políticas e sociais. Milhares de refugiados sírios, assim como de outras realidades de instabilidade bélica, têm empreendido um êxodo sem precedentes no pósSegunda Grande Guerra Mundial, fugindo à perigosidade dos conflitos armados no país de origem, em busca de refúgio seguro em países da Europa do Sul e Central. 0 desespero tem feito milhares de vítimas na travessia por via marítima, assim como originou situações de tensão e confronto em determinadas fronteiras terrestres com políticas migratórias mais rígidas, como por exemplo no caso da Hungria.

A opinião pública tem construído a sua visão do fenómeno com base nas informações vinculadas pela Comunicação Social, assim como por organismos como o AltoComissariado para as Nações Unidas para os Refugiados (ACNUR) Números e explicações concretas sobre o fenómeno são apenas uma aproximação da realidade, o que se compreende quer pela extraordinária dimensão quantitativa do fenómeno, quer pela própria dinâmica de mobilidade, a qual rapidamente encontra novas rotas e estratégias de deslocação. No caso português, que de uma forma geral replica o pensamento europeu, nota-se dupla tendência:

- De solidariedade) Há grupos organizados, em conjunto com ONG, que manifestam disponibilidade em ajudar os refugiados no processo de acolhimento. Por exemplo, a "Plataforma de Apoio aos Refugiados" conta com a agregação de um conjunto de organismos que, em conjunto, estão a definir estratégias de apoio aos deslocados. "Há a noção da urgência da ação humanitária, que pede uma resposta imediata de acolhimento, sem ignorar as intervenções com impacto a médio-longo prazo, como a estabilização política, económica $e$ social das zonas de crise" (PAR, 2005).

Também a sociedade civil, em reação espontânea, começa a evidenciar iniciativas de ajuda pontual (por exemplo, através da oferta de roupa e bens alimentares em instituições religiosas com a finalidade de distribuir pelos refugiados que serão acolhidos; a ida de um grupo de portugueses a uma das áreas de fronteira, o qual conseguiu trazer uma família síria para Portugal).

- De repulsa) Estão a decorrer on-line petições como a "Não aos refugiados em Portugal" e "Pelo fim imediato da entrada de refugiados em Portugal" (Petição on-line, 2015), onde se advoga que o país deve concentrar o seu apoio aos nacionais, não os aplicando em estrangeiros oriundos de outras realidades políticas, culturais e religiosas. Do ponto de vista do posicionamento político, a extrema-direita (PNR, 2015) é contra a o acolhimento de refugiados no país tanto pelas questões económicas enunciadas, como pela salvaguarda da segurança nacional e da luta contra o terrorismo.

Assim, este artigo tem como objetivo realizar uma reflexão introdutória sobre o posicionamento das migrações na teoria dos riscos, em particular deste fluxo contemporâneo de refugiados que chega ao sul da Europa por via do Mar Mediterrâneo, tendo em conta a importância do estudo das convulsões sociais na lógica do risco-perigo-crise.

Para isso serão apresentadas as visões de autores como Faugèrs (1990), Lourenço (2007, 2013, 2015), Fernandes (2008, 2013), Bolas (2012), Fernandes (2012), Areosa (2008), Herculano (2009) e Rodrigues (2010), e de organismos como o Alto-Comissariado das Nações Unidas para os Refugiados (2015), Plataforma de Apoio aos Refugiados (2015) e o Serviço de Estrangeiros e Fronteiras (2015).

\section{A posição das migrações (forçadas) na teoria dos riscos}

Lourenço (2015: 28-38), influenciado pelos trabalhos de Faugères (1990: 53), identifica uma tipologia dos riscos e das catástrofes, tendo em conta a sua génese. São três os grandes grupos, nomeadamente os dos "riscos naturais", referentes a diversos fenómenos naturais capazes de produzir danos; "riscos antrópicos", que dizem respeito a fenómenos que causam danos em resultado da intervenção do ser humano no seu ambiente natural; "riscos mistos", os quais resultam tanto de condições naturais como de ações antrópicas.

Os riscos antrópicos dividem-se em dois sub-grupos. Os "riscos tecnológicos", que resultam do desrespeito pelas normas de segurança e pelos princípios associados à produção, manuseamento, transporte e armazenamento de certos produtos. Já os "riscos sociais" resultam da incapacidade do ser humano viver de forma harmoniosa no seio da sua comunidade, desrespeitando princípios os básicos da igualdade, fraternidade e liberdade face ao seu semelhante. Este tipo de riscos, segundo Lourenço (2007: 111), tem vindo a ganhar importância, tendo em conta as atuais circunstâncias da crise económica e, agora, pela emergência de gestão dos fluxos emergentes e consubstanciados de refugiados na Europa.

No âmbito dos riscos antroposociais identificam-se ainda três subgrupos. O primeiro dos "riscos associados a ecossistemas urbanos e rurais", os quais se concretizam 
na perturbação do regular funcionamento dos sistemas urbanos e rurais (por exemplo, a delapidação do solo, destruição da fauna e da flora, etc.). No contexto da abordagem em causa, a análise da crise migratória europeia posiciona-se, do ponto de vista da teoria dos riscos, nos sub-grupos seguintes (Lourenço, 2015: 33-34):

- [...] "Riscos associados a convulsões sociais [relacionados com situações de] desemprego, subemprego generalizado, fome e desnutrição, migrações intensas e descontroladas, infância e juventude marginalizadas ou carentes, especulação, greves generalizadas, disseminação de boatos, tumultos e desordens [...], incremento dos índices de criminalidade e assaltos, banditismo e crime organizado, colapso do sistema penitenciário, sabotagem e terrorismo, perseguições e conflitos ideológicos, religiosos e raciais.

- [...] Riscos associados a conflitos bélicos [...] incluem desde guerras internas, civis e revolucionárias, até guerras convencionais, passando pelas [...] guerras nucleares, radioativas, biológicas e químicas."

Autores como Areosa (2008: 11), na área dos riscos sociais, e Hunter (2004: 6), Fernandes (2008: 15; 2013: 658) e Pacifico e Gaudêncio (2014: 137), com trabalhos sobre refugiados ambientais, dão um contributo importante a partir dos seus estudos, os quais permitem uma reflexão mais aprofundada da posição das migrações na teoria dos riscos, como se pode verificar na fig. 1 .

Neste sentido, pode-se considerar que, além das migrações intensas e descontroladas estarem incluídas no grupo dos riscos antrópicos/subgrupo dos riscos sociais associados a convulsões sociais e a conflitos bélicos, a origem motivacional da deslocação pode posicioná-las de outra forma na teoria dos riscos, nomeadamente se tiver origem num processo ambiental. A erupção de um vulcão, um terramoto, uma inundação, um deslizamento de terras, um tornado, um tsunami, entre outros fenómenos ambientais, podem dar origem a deslocações massivas de população, com o objetivo de preservar a segurança física de si e dos seus. Face a esta situação, e tendo em conta Herculano (2009: 5), as migrações forçadas, as quais geram fluxos mais ou menos intensos de deslocados e refugiados, parecem estar contempladas até certo ponto pela dimensão dos riscos mistos, na medida em que a deslocação pode resultar tanto de ações humanas como da natureza.

Mesmo não atuando em simultâneo, o facto é que este grupo reage a ambos os tipos de estímulos - naturais e antrópicos. A deslocação é assim uma forma de resiliência ex loco, em que os indivíduos respondem às consequências do processo de desterritorialização, com base na deslocação para espaços que consideram (mais) seguros (Fernandes, 2008:16). A migração é, nestes casos, entendida como uma estratégia de reterritorialização a curto-prazo.

Uma abordagem da crise do mediterrâneo do ponto de vista antroposocial

\section{Contextualização da crise migratória do Mediterrâneo} e da Europa

Tendo em conta a génese bélica da crise migratória europeia, o foco da análise será concebida numa perspetiva de risco antroposocial, pois a causa da deslocação de grande parte dos migrantes que tem vindo a chegar à Europa está relacionado com o conflito

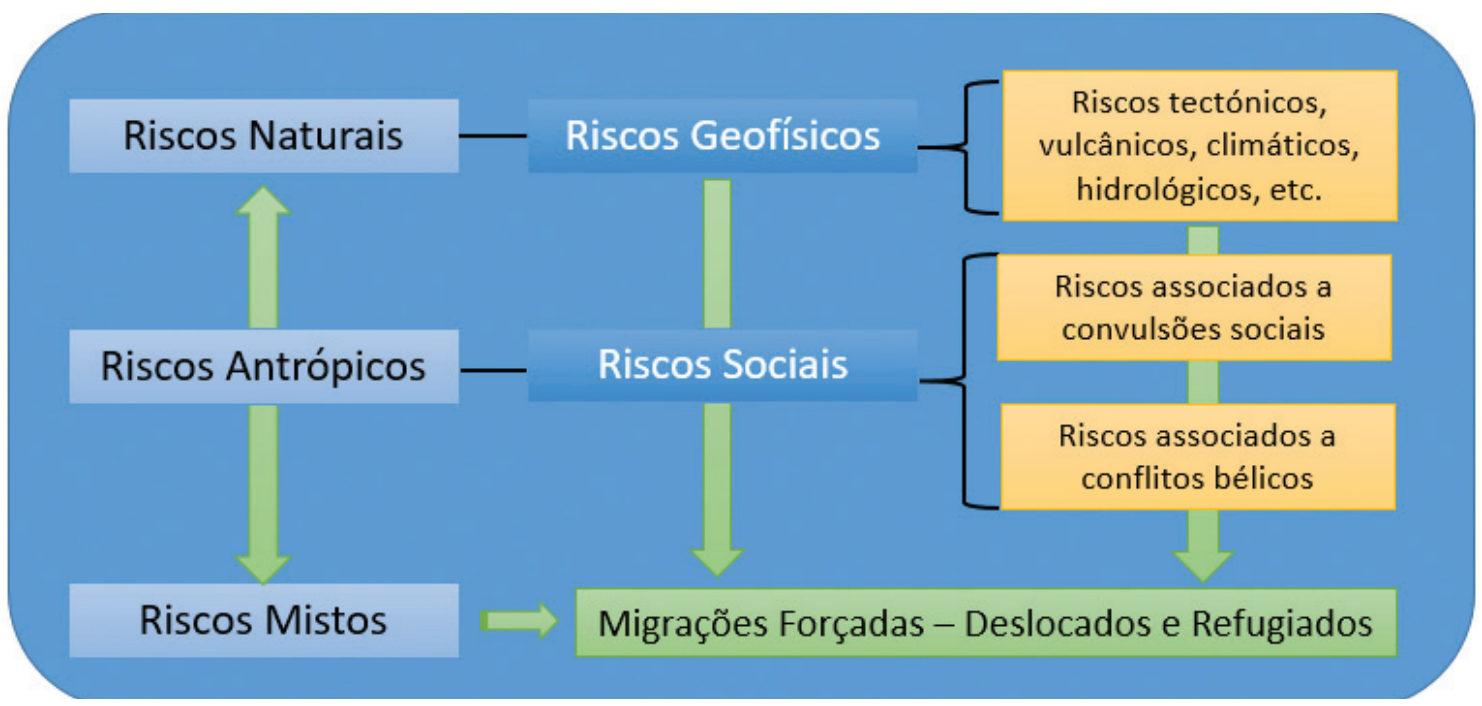

Fig. 1 - As migrações na teoria dos riscos.

Fig. 1 - The migrations in the risk's theory. 
bélico da Síria. O foco da análise centra-se na região do Mediterrâneo por ter sido uma das primeiras zonas críticas de receção destes refugiados, continuando a ser um dos principais locais de chegada destes grupos.

No início da crise atual, o processo começou por ser conduzido por redes de tráfico humano, onde os traficantes recrutavam indivíduos em fuga a situações de conflito, com os quais acordavam, perante pagamentos indevidos, fazer a travessia "incompleta" do mar Mediterrâneo, ou seja, bastava que atingissem águas internacionais para que fosse solicitado auxílio às Autoridades Marítimas do respetivo país. Na prática, estas situações de perigo vieram dar origem a uma crise no mediterrâneo, pois as forças armadas, em especial a marinha dos respetivos países, não conseguiam dar resposta a todas as solicitações. Além disso, os traficantes rentabilizaram o tráfico humano, permitindo a sobrelotação de barcos sem prover as condições de segurança adequadas, o que veio a resultar numa catástrofe humanitária de grandes dimensões, com a morte por afogamento de muitos dos ocupantes. Embora se tenha verificado nos últimos meses um incomensurável aumento do número de migrantes refugiados, em especial por via terrestre, a análise fenomenológica centrar-se-á nos que continuam a chegar fazendo a travessia por rotas marítimas no Mediterrâneo, por se entender que esta escolha evidencia um maior grau de perigo para a segurança física dos indivíduos.

O enfoque da análise será sobre os sírios, tanto pela preponderância numérica, como pelo perfil estrutural da própria migração, que inclui uma deslocação em grupo do agregado familiar de proximidade (casal e filhos), na mesma dimensão cronotópica. Para esta população, a saída dá-se em contexto de crise, pois a fase do risco e do perigo já está materializado em situações reais de insegurança no local de origem (por exemplo bombardeamentos, colapso do sistema de ensino e de saúde, falta de bens essenciais, pilhagens, etc.). A migração forçada surge como resposta à crise, ou seja, os sujeitos desenvolvem características resilientes, em duas dimensões:

- $\quad$ Temporal - tanto reativa (caso a fuga se dê na sequência de um facto que tenha gerado uma situação de crise ou catástrofe, por exemplo um bombardeamento com perda de vidas) como antecipativa (quando, pelo contexto de insegurança, a migração ocorre no sentido preventivo);

- $\quad$ Espacial - ex-loco, na medida em que ocorre a deslocação fora do cenário de guerra, neste caso com necessidade de mudança de residência para um país terceiro.

A resiliência manifestada é de natureza individual, pois cada indivíduo/família opta por estratégias de fuga diferenciadas, sendo que a escolha da via marítima pode ter como justificativa a aparente facilidade de deslocação geográfica, já que implica, à partida, a ideia de menos esforço físico e de menores constrangimentos burocráticos ao nível fronteiriço. Mas na prática, a violência da travessia revela-se (ainda mais) perigosa do que a realização de rotas terrestres. Também pelo facto de ser um movimento de grupo se pode considerar com uma forma de resiliência comunitária, já que se trata de um movimento sistemático de massas, contudo sem ter

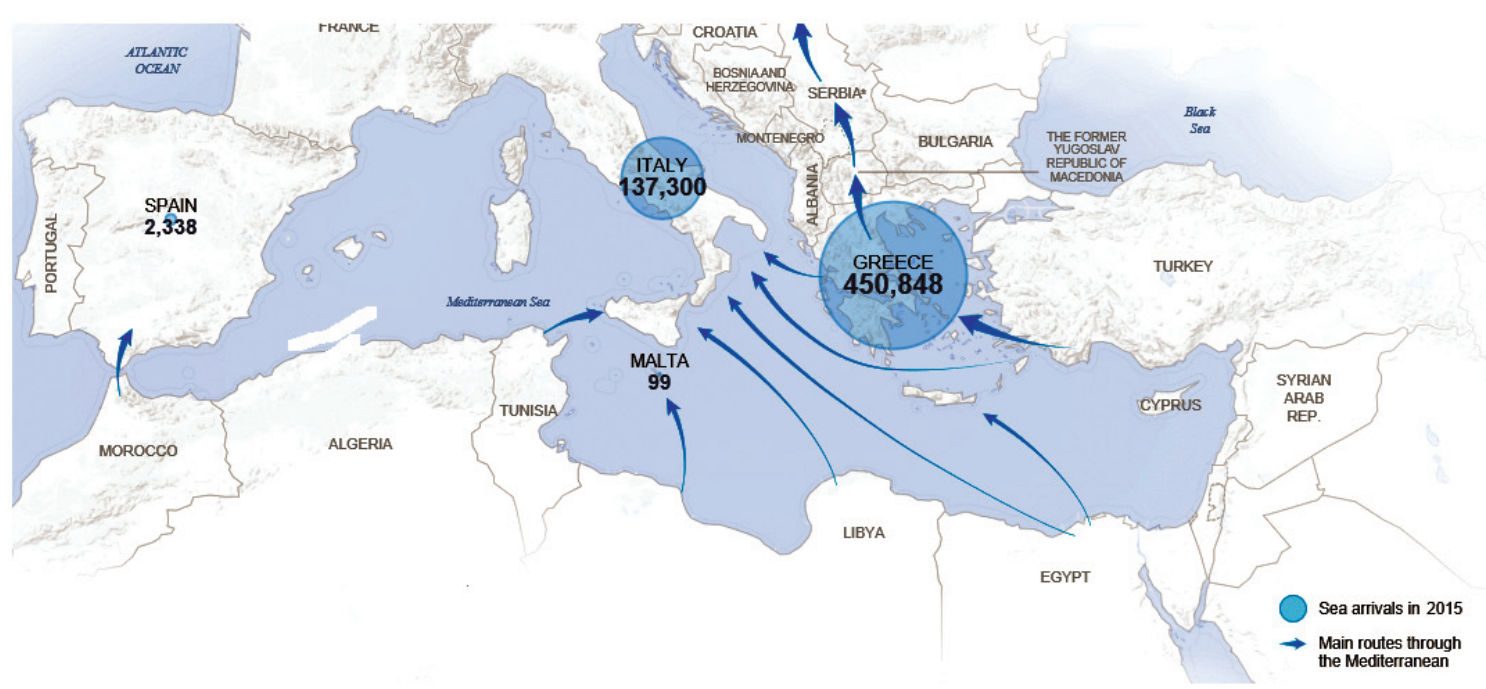

Fig. 2 - Mapa esquemático dos fluxos de refugiados no Mediterrâneo (valores de Janeiro a Outubro de 2015 (Fonte: ACNUR, 2015).

Fig.2 - Schematic map of the refugee flows in the Mediterranean (values January-October 2015) (Source: ACNUR, 2015). 
resultado de uma estratégia de cariz formal, portanto sem uma organização prévia devidamente estruturada e oficializada de deslocação conjunta organizada.

O ACNUR (2015) estima que este ano tenham chegado à Europa, por via marítima (fig. 2), 590.585 indivíduos, estando oficialmente registados 3.095 mortos/ desaparecidos. Refira-se que este último valor não é conclusivo, uma vez que não há registo oficial das saídas, o que impede que se chegue a um número válido, daí que se estime que o número de vítimas seja muito mais elevado. Da totalidade das chegadas por via marítima, $83 \%$ são oriundos dos 10 países com o maior número de refugiados fora das suas fronteiras de origem: $54 \%$ são sírios; $15 \%$ são afegãos; $6 \%$ eritreus; $4 \%$ iraquianos.

Em termos de género/idade dos que conseguem atingir a Europa através do mar Mediterrâneo, 68\% são homens, $13 \%$ mulheres e $19 \%$ são crianças.

Como se pode verificar na fig. 3, comparativamente a 2014, o fluxo migratório de refugiados aumentou muito em 2015. Segundo dados do ANCUR (2015), a diferenciação começou a partir do mês de Abril deste ano, tendo vindo a aumentar de forma significativa ao longo dos meses. Uma análise à escala regional permite perceber que há situações diferenciadas quer em termos de número, quer em termos de origem dos migrantes. A Grécia é um caso em destaque, visto ser o principal destino de sírios que empreendem a viagem para a Europa por via marítima.

\section{O caso da Grécia}

Tendo em conta a totalidade dos migrantes chegados à Europa por via marítima do Mediterrâneo, a Grécia recebeu de Janeiro a meados de Outubro $76 \%$ desse contingente, ou seja, 450.848 indivíduos (fig. 4). Do total desses estrangeiros, $94 \%$ são oriundos dos 10 países com o maior número de refugiados fora das suas fronteiras de origem, com destaque para os sírios (69\%) e para os afegãos (19\%).

Em termos de género/idade os valores são semelhantes ao que se passa em geral no Mediterrâneo: $66 \%$ são homens, $13 \%$ mulheres e $21 \%$ são crianças. Esta tendência é seguida de forma similar no que diz respeito ao número de chegadas, ou seja, tem-se registado um aumento ao longo dos anos, ultrapassando-se as 150.000 chegadas no mês de Agosto.

A localização geoestratégica da Grécia, na fronteira com a Turquia e próxima do norte de África, torna-se um destino inevitável na rota dos refugiados os quais, vindos por via terrestre, aproveitam o sistema insular do país para chegar à União Europeia por águas internacionais.

Estes migrantes oriundos de zonas de conflito, em fuga a situações de risco-perigo e como reação à factualidade da crise política, económica e social, em especial do conflito armado na Síria, acabam por ser geradores de um contexto de risco para as ilhas/regiões de fronteira grega, pois a sua presença desencadeia um conjunto de processos que coloca em causa o funcionamento do território, tornando real a suscetibilidade de acarretar prejuízos diretos ou indiretos aos autóctones (Faugères, 1990: 53). Há várias situações em casa: a rutura no consumo de bens básicos; a falta de acesso a infraestruturas essenciais (por exemplo, a rede de água - potável) e a serviços básicos (por exemplo, de saúde); a incapacidade de acolhimento habitacional; conflitos com as populações locais, etc.

Nesse sentido, o ACNUR e a UE têm tentado dar resposta através da atuação conjunta com ONG em áreas críticas, onde a concentração de refugiados é mais elevada, dando apoio em várias áreas, nomeadamente: infraestruturas e habitação; saúde; serviços de emergência; proteção; higiene; serviços administrativos; transporte.

\section{Comparison of monthly Mediterranean sea arrivals $\square 2014 \quad \square 2015$}

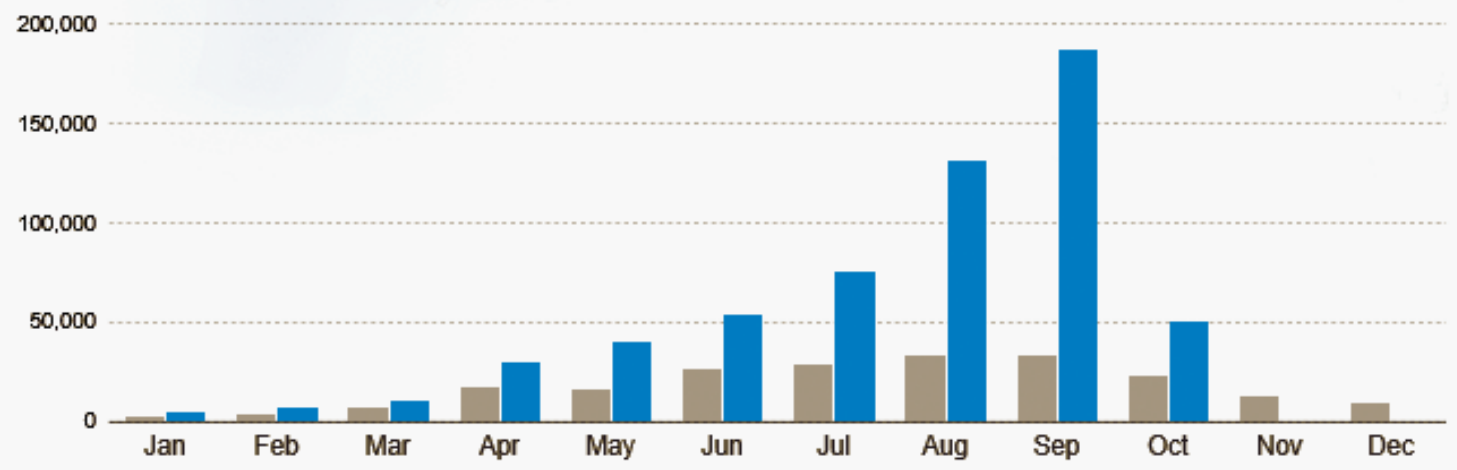

Fig. 3 - Os fluxos migratórios no mar Mediterrâneo (comparação 2014-2015) (Fonte: ACNUR, 2015).

Fig.3 - The migratory flows in the Mediterranean Sea (comparison 2014-2015) (Source: ACNUR, 2015). 


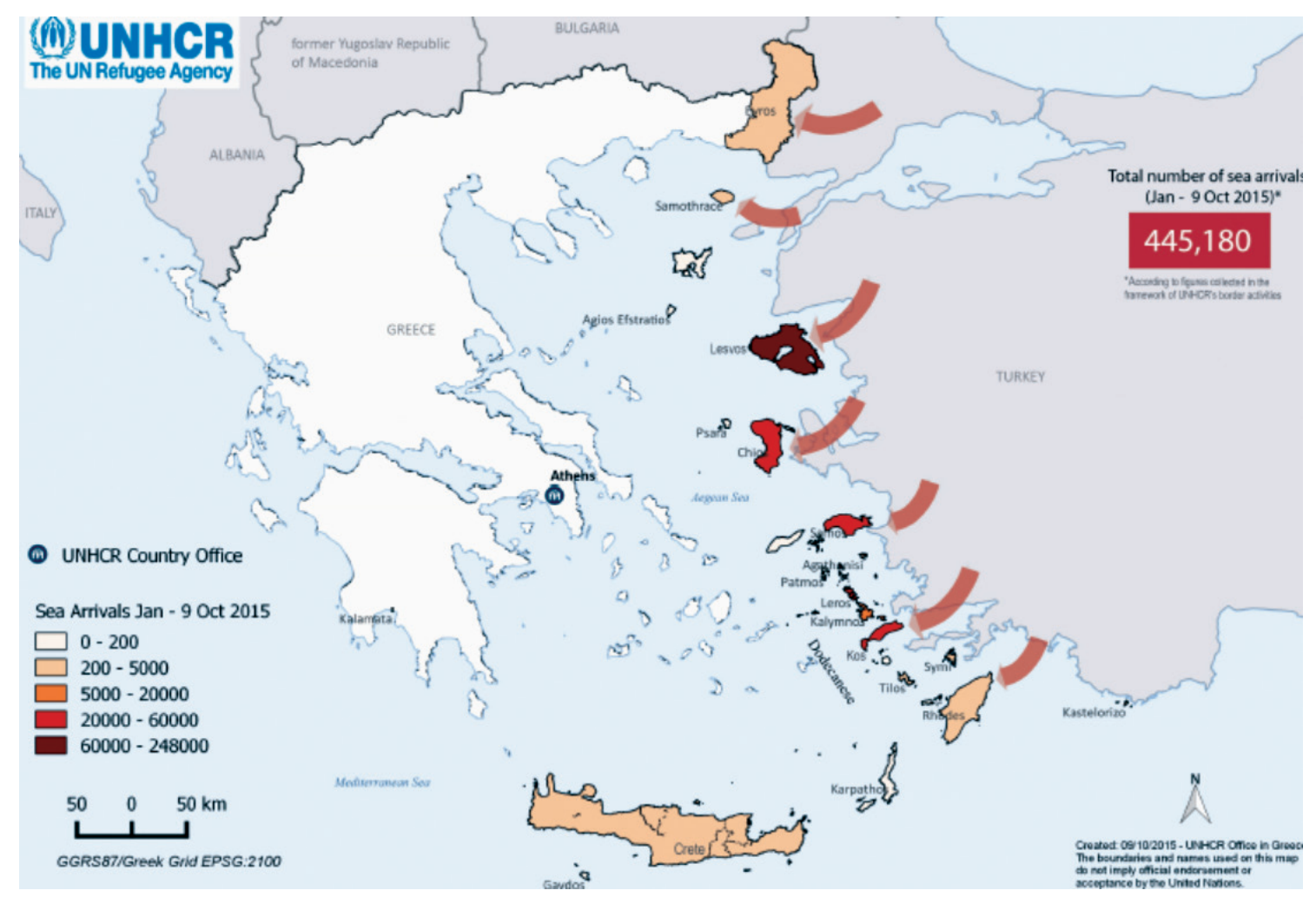

Fig. 4 - Chegadas por via marítima (Janeiro-Outubro, 2015) (Fonte: ACNUR, 2015).

Fig.4 - Sea arrivals (January-October, 2015) (Source, ACNUR, 2015).

Migrantes ou refugiados? A importância do estatuto para a integração no território de acolhimento

A terminologia usada pela opinião pública para fazer referência a estes indivíduos não é consensual. É comum a comunicação social e a sociedade civil usarem o termo "migrante" ou "refugiado", de forma indistinta, embora se trate de situações relativamente distintas.

Um migrante (seja emigrante ou imigrante) é definido pela Organização Internacional das Migrações (2015) como um indivíduo que se desloca do seu local de residência para uma determinada finalidade (trabalhar, estudar, etc.) por um período igual ou superior a um ano. Este é um conceito generalista, embora haja situações específicas que urge diferenciar, tendo em conta a génese, a motivação, dinâmica e cronotopia do processo migratórios. Por exemplo, alguém que empreenda um movimento com as características enunciadas, cuja finalidade seja a de trabalhar, é um "migrante laboral"; se a migração for inferior a um ano, pode-se considerar que estamos perante um caso de "migração sazonal”.

No caso dos refugiados, será mais correto considerar que, mais do que uma tipologia, se está perante um estatuto atribuído a um deslocado, ou seja, a alguém que saiu involuntariamente da sua área de residência, e que pode requerer asilo a um país terceiro (SEF, 2008: 11).
O Estatuto de Refugiado foi adotado em 28 de Julho de 1951 pela Conferência das Nações Unidas de Plenipotenciários sobre o Estatuto dos Refugiados e Apátridas, tendo entrado em vigor em 22 de Abril de 1954. Considera-se que um refugiado é "alguém que, temendo ser perseguido por motivos de raça, religião, nacionalidade, grupo social ou opiniões políticas, se encontra fora do país da sua nacionalidade e que não pode ou, em virtude desse temor, não quer valer-se da proteção desse país" (ACNUR, 2015).

Em termos tipológicos reúne três dimensões migra-tórias (fig. 5), sendo "familiar" no caso de haver acompanhamento ou reunificação do agregado; “humanitária” com base nos pressupostos cons-tituídos pelos direitos fundamentais do ser humano, nomeadamente o da segurança; é “económica” por-que a deslocação pressupõe a fixação noutro país e a continuidade das vivências quotidianas, onde se inclui o direito e a necessidade de trabalho para sustento próprio.

No caso concreto dos indivíduos entrados na Europa pela via do Mediterrâneo, a maior parte foge de um contexto de guerra (sírios e afegãos), pelo que lhes está a ser concedido o estatuto de refugiado. Mais do que a designação em si, a qual permite a noção de pertença a um grupo em termos identitários e simbólicos, é 


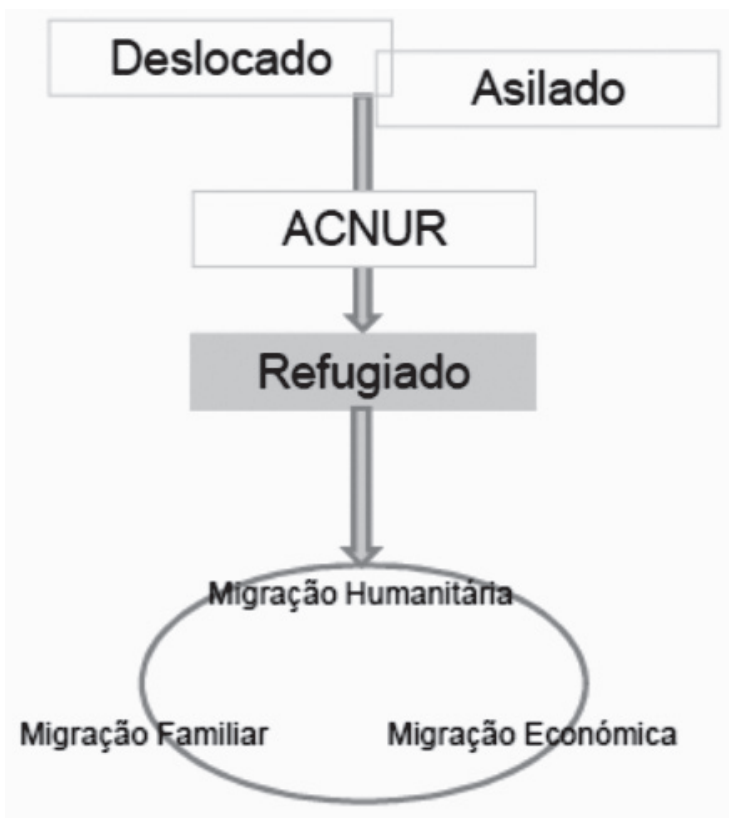

Fig. 5 - 0 estatuto de Refugiado.

Fig. 5 - The Refugee status.

importante o efeito prático, pois além dos deveres para com o país de acolhimento (respeito pelas leis), é-lhes concedido um conjunto de direitos, nomeadamente:

- Não discriminação quanto ao género, raça e religião;

- $\quad$ Residência;

- Acesso aos serviços de educação, saúde, justiça, etc.

- Trabalho remunerado e segurança social;

- Liberdade de movimento (com reservas instituídas pela regulamentação aplicável aos estrangeiros em geral na mesma situação);

- $\quad$ Papéis de identidade.

A Convenção Relativa ao Estatuto dos Refugiados (1951) (2015: 7) consigna ainda uma cláusula para a via marítima que refere "no caso de refugiados empregados como membros da equipagem a bordo de um navio que hasteie pavilhão de um Estado Contratante, esse Estado examinará com benevolência a possibilidade de autorizar os referidos refugiados a se estabelecerem no seu território e a entregarlhes documentos de viagem ou de os admitir a título temporário no seu território, a fim, notadamente, de facilitar a sua fixação em outro país."

No caso do Mediterrâneo a vinda é clandestina, precária, sem respeitar qualquer protocolo marítimo, todavia o contexto de fuga massiva de cenários bélicos de grande violência tem levado a ACNUR e União Europeia a aceitar estes migrantes, a atribuir-lhes o estatuto de "refugiados" e a discutir locais, quotas e procedimentos com vista ao seu acolhimento.

\section{A fuga à crise e o risco antroposocial}

A análise das migrações contemporâneas - refugiados que chegam pela via marítima do Mediterrâneo - leva a equacionar alguns riscos antroposociais que poderão derivar da sua presença no território de acolhimento, nomeadamente em países europeus. O estudo de Rodrigues (2010: 36), em que cita Weiner (1995), defende que há um conjunto de ideias pré-concebidas pelas sociedades recetoras, sobretudo de quadrantes sociopolíticos que tendem a encarar os refugiados como uma ameaça. A autora identifica cinco tendências de conceção deste "outro", considerando-se que:

- Minam as relações entre o país de origem e o de destino, sobretudo quando se opõem ao regime do país de origem);

- Afetam a vida política e a segurança do país de acolhimento;

- $\quad$ São um perigo para a cultura dominante e para a identidade nacional;

- Se asseguram como um problema social e económico para o país de destino, exercendo pressão nos sistemas laborais e de segurança social, entre outros;

- Podem manipular a opinião pública contra o país de origem.

Velez de Castro (2014: 113) cita Stalker (2000), uma vez que este autor sistematizou as vantagens e desvantagens da presença de migrantes para os territórios e sociedades emissoras e recetoras. Embora a sua visão seja uma abordagem geral, para todos os tipos de fluxos, é possível particularizar a questão dos refugiados. Para este autor, há um conjunto de risco antroposociais que podem estar associados à presença destes estrangeiros em territórios de acolhimento, nomeadamente:

1) Risco de discriminação racial e xenófoba - o receio das populações autóctones sobre questões de (in)segurança ligados ao terrorismo, pode associar os refugiados, pela origem nacional e racial, a potenciais movimentos extremistas;

2) Risco de fricção social - decorrente da eventual intensificação da presença destes estrangeiros, em espaços de "não-pertença", isto é, como utilizadores de serviços, equipamentos e bens, que pode gerar momentos de obturação de processos e diligências; 
3) Risco de isolamento/separação familiar - nos casos em que houve rutura da unidade familiar antes da partida ou durante a viagem. É desejável a reunificação, ainda que possa ser bastante difícil a reagregação de todos os membros.

4) Riscos associados ao mercado de trabalho a inclusão laboral preconizada pelo estatuto de refugiado pode causar constrangimentos neste sector, uma vez que se trata de um fluxo de grandes dimensões, que teve um êxodo rápido, sendo que os territórios de chegada podem ter dificuldades em absorver a mão-de-obra ativa refugiada. Além disso, e dado o possível excedente demográfico, a disponibilidade da oferta pode diminuir os salários à escala local;

5) Riscos associados a custos sociais - pode acarretar custos mais elevados que o previsto, para a dinâmica territorial habitual, em vários sectores (educação, saúde, segurança social, etc.);

6) Risco de formação de guetos - a localização, sobretudo em áreas urbanas, associado à concentração de determinados grupos, pode levar a situações de exclusão social, dificultando o processo de integração sociocomunitário.

Sobre esta questão, Bolas (2012: 55) defende que a localização geográfica dos refugiados num país, em estreita relação com as comunidades locais, afeta de forma significativa a experiência da integração e o risco de exclusão em termos de acesso aos serviços, às redes sociais e à criação do sentido de pertença. Daí que a estratégia política deva passar em grande parte por uma abordagem geográfica adequada, ainda que possível.

No sentido da mitigação dos riscos, organismos como o ACNUR (2014: 19) defendem uma ação integrada de vários atores a várias escalas, sendo muito desejável a criação de mecanismos, nos próprios países de acolhimento, que apoiem o retorno ao país de origem dos refugiados, assim que se voltem a verificar condições de segurança. Esta premissa é muito importante, pois sistematiza o verdadeiro significado de "refugiado-indivíduo" e "refúgio-lugar", criando condições para uma permanência alóctone digna, mas também para o retomar da vida e quotidianidade no local de partida.

\section{Considerações finais}

A intensificação da entrada de refugiados na Europa, pela via marítima do Mediterrâneo, trouxe novas preocupações e desafios à sociedade europeia. Se por um lado é impreterível e urgente acolher os que procuram territórios onde possam viver em segurança, por outro é necessário equacionar os riscos antroposociais derivados da chegada massiva e rápida destes fluxos.

A atuação das forças armadas nacionais, de ONG e de organismos como o ACNUR têm sido essencial, já que auxiliam na(s) fronteira(s) de crise, numa tentativa de dar uma primeira resposta às necessidades mais prementes dos refugiados. Todavia é preciso equacionar os riscos que poderão advir da presença destas populações em fuga a situações de conflito, de forma a dar respostas resilientes e adequadas e a evitar a génese de (novas) crises em territórios recetores.

\section{Referências bibliográficas}

ACNUR (2014). World at war. Global trends 2014, UNHCR, $56 \mathrm{p}$.

ACNUR (2015). Alto-Comissariado das Nações Unidas para os Refugiados. Disponível em: http:// www. acnur.org/t3/portugues/informacaogeral/alto-comissario-das-nacoes-unidas-pararefugiados/ (acedido em 15/10/2015)

Aresosa, João (2008). O risco no âmbito da teoria social, VII Congresso Português de Sociologia, Lisboa, 1-16 pp.

Bolas, Maria Teresa Caiado (2012). Direitos humanos $e$ movimentos sociais, Mestrado em Antropologia, Faculdade de Ciências Sociais e Humanas da Universidade Nova de Lisboa, $120 \mathrm{p}$.

CRER (2015). Convenção Relativa ao Estatuto dos Refugiados (1951). Disponível em: http://www.acnur. org/t3/fileadmin/Documentos/portugues/ BDL/Convencao_relativa_ao_Estatuto_dos Refugiados.pdf?view=1 (acedido em 15/10/2015)

Faugères, Lucien (1990). La dimension des faits e la théorie du risqué. Le Risque et la Crise. European Coordination Centre for Research and Documentation in Social Sciences, Foundation for International Studies, Malta, p.31-60.

Fernandes, João Luís (2008). Insegurança ambiental e migrações. Contributo para uma sistematização de conceitos, Actas del V Congreso Internacional sobre migraciones, causas y consecuencias, Eumed, Universidade de Málaga, p.1-20.

Fernandes, Jorge Manuel Lopes (2012). Conflitos e processos de desterritorialização / reterritorialização. O caso dos refugiados, Mestrado em Geografia Humana, Faculdade de Letras da Universidade de Coimbra, $160 \mathrm{p}$.

Fernandes, João Luís (2013). A desterritorialização enquanto risco antrópico. Análise a propósito da representação da insegurança nos filmes Still Life e Home (2008), in: Lourenço, Luciano; Mateus, Manuel (Coord.), Riscos naturais, antrópicos e mistos. Homenagem ao Professor Doutor Fernando Rebelo, Departamento de Geografia, Faculdade de Letras, Universidade de Coimbra, pp.653-666.

Herculano, André Garibaldi (2009). A intervenção social num contexto de riscos naturais, tecnológicos e sociais, Atas das II Jornadas de Educação Social, Bragança, 1-18 pp. 
Lourenço, Luciano (2007). Riscos naturais, antrópicos e mistos, Territorium, 14, p.109-113. Disponível em: http://www.uc.pt/fluc/nicif/ riscos/Documentacao/Territorium/T14_artg/ T14NNR01.pdf.

Lourenço, Luciano; Mateus, Manuel (Coord.) (2013), Riscos naturais, antrópicos e mistos. Homenagem ao Professor Doutor Fernando Rebelo, Departamento de Geografia, Faculdade de Letras, Universidade de Coimbra, 902 p.

Lourenço, Luciano (2015). Risco, perigo, crise: pragmatismo e contextualização. Riscos de desastres relacionados à água: aplicabilidade de bases conceituais das Ciências Humanas e Sociais para a análise de casos concretos (organizado por Antenora Siqueira, Norma Valêncio, Mariana Siena, Marco António Malagoli), S.Paulo, RiMa Editora, p.3-43.

PAR (2015) - PLATAFORMA DE APOIO AOS REFUGIADOS. Disponível em: http://www.refugiados.pt/ (acedido em 12/10/2015).

OIM (2015) - ORGANIZAÇÃO INTERNACIONAL PARA AS MIGRAÇÕES. Disponível em: http://www.iom.int/ (acedido em 15/10/2015)
Petição on-line (2015) - Não aos refugiados em Portugal. Disponível em: http://peticaopublica. com/pview.aspx?pi=PT78297 (acedido em $12 / 10 / 2015$ )

Petição on-line (2015) - Pelo fim imediato da entrada de refugiados em Portugal. Disponível em: http: / / peticaopublica.com/pview.aspx?pi=PT78324 (acedido em 12/10/2015)

Rodrigues, Teresa Ferreira (2010). Dinâmicas migratórias e riscos de seguranca em Portugal, Instituto da Defesa Nacional, Lisboa, 108 p.

SEF - SERVIÇO DE ESTRANGEIROS E FRONTEIRAS (2008). A organização das políticas de asilo $e$ de imigração em Portugal, Sef-Comissão Europeia, Lisboa, 58 p.

SEF - SERVIÇO DE ESTRANGEIROS E FRONTEIRAS (2015). Disponível em: http://www.sef.pt/portal/ v10/PT/aspx/page.aspx (acedido em 15/10/2015).

Velez de Castro, Fátima (2014). Imigração $e$ desenvolvimento em regiões de baixas densidades, Imprensa da Universidade de Coimbra, Coimbra, 477 p. 

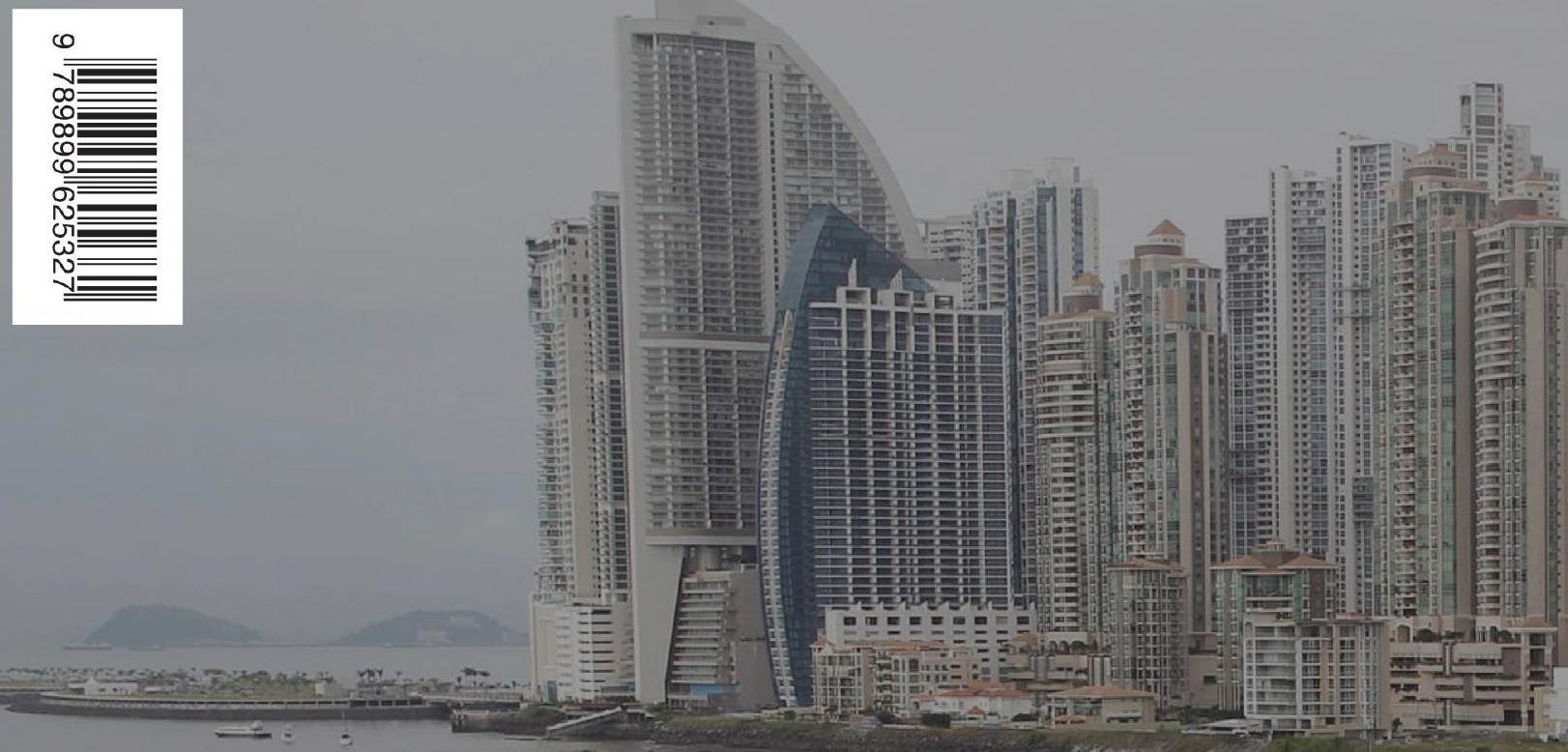

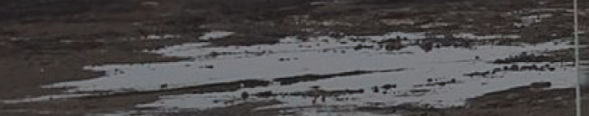

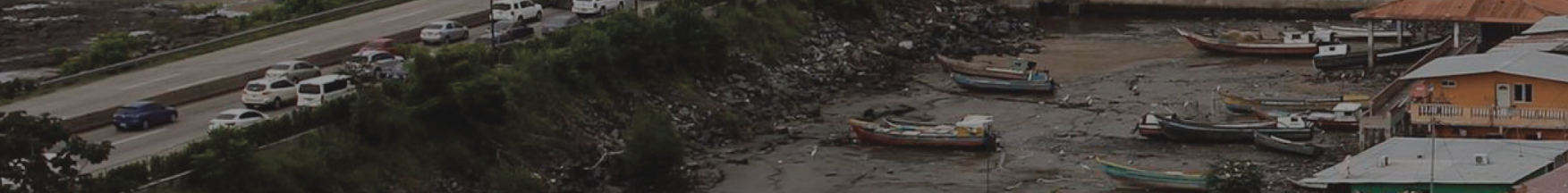

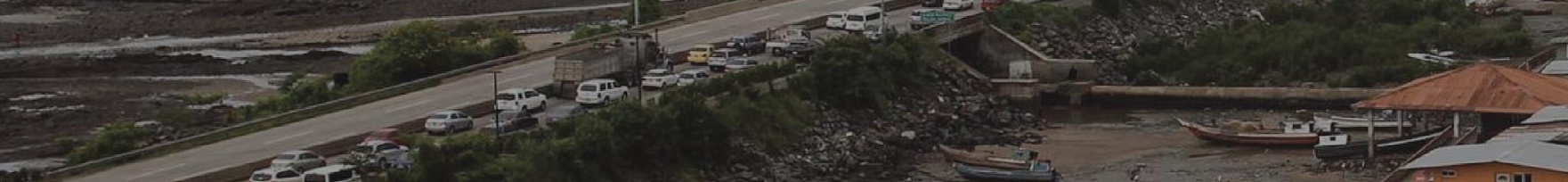
inse- $n=$ Riscos I I I

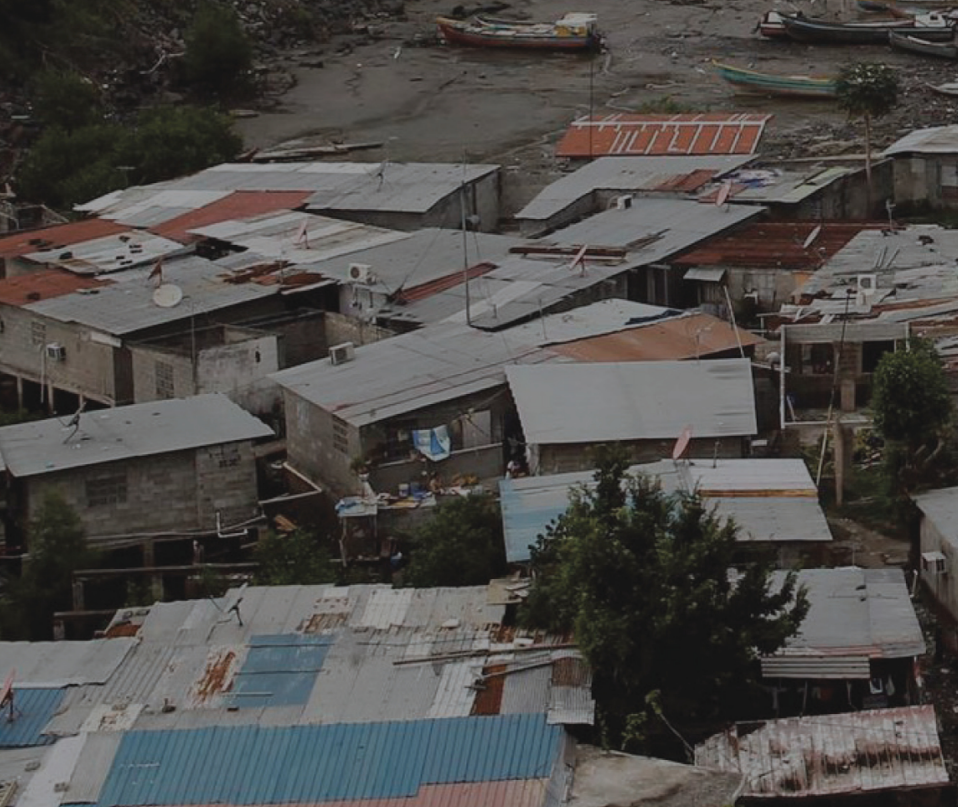

